\title{
DEMOTISCHE TEXTE AUF KRÜGEN
}

HERAUSGEGEBEN UND ERKLÄRT

voN

\section{WILHELM SPIEGELBERG}

\author{
MIT EINER LICHTDRUCK- UND ACHT STEINDRUCKTAFELN \\ IN BESONDEREM FOLIO-UMSCHLAG
}

\section{LEIPZIG}

J. C. HINRICHS'SCHE BUCHHANDLUNG

19 I 2 


\section{DEMOTISCHE STUDIEN}

VON

WILHELM SPIEGELBERG

HEFT $\dot{5}$

Foto - Lito - DINI - Modena - 1977 


\section{Inhaltsverzeichnis.}

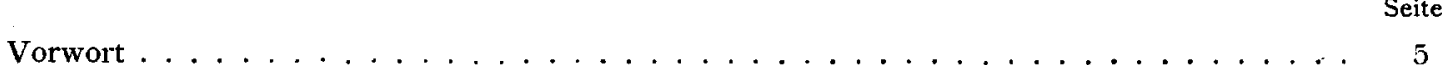

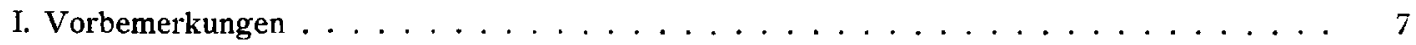

1. Die Herkunft und Datierung der Texte . . . . . . . . . . . . . 7

2. Der Inhalt der Texte . . . . . . . . . . . . . . . . 7

3. Der literarische Charakter der Texte . . . . . . . . . . . . . . 12

II. Umschrift und Übersetzung der Texte . . . . . . . . . . . . . . . . . . . . . . . . . . 14

III. Kommentar . . . . . . . . . . . . . . . . . . . . . . . . 25

IV. Fortlaufende Handkopie der Texte A. B. und C . . . . . . . . . . . . . . 48

V. Glossar . . . . . . . . . . . . . . . . . . . . . . . . 58-81

VI. Tafeln: Die Krugaufschriften in Facsimile . . . . . . . . . . . . . Tafel I-VIII

Krug A, drei Ansichten in Lichtdruck nach Photographien . . . . . . . . Tafel IX (Die Tafeln sind in besonderem Folio-Umschlag beigegeben.) 
